\title{
Chapter 48 \\ THE DEVELOPMENT OF COAST PROFILES ON A RECEDING COAST PROTECTED BY GROYNES
}

\author{
Torben Sørensen \\ Research Engineer, Casstal Engineering Laboratory \\ Technical University of Denmark, Capenhagen, Denmark
}

This paper presents an analysis of the longshore sand transport by waves and current on natural coast outside the breaker zone. A tentative expression for the transport capacity is established and applied to the problem of the effect of groynes on the development of the const profiles. It is shown that the results are consistent with the observed development of the Banish North Sea Coast at Thyboran, which has been protected by groynes and closely obaerved through the last 60 years.

\section{IMTRODUCTION}

When continuously receding andy coast is protected by groynes the immediate result is a considerable reduction of the rate of recession of the coastline chiefly due to a reduction in the beach drift. This fact is generally accepted and has been confirmed empirically under protatype conditions.

However some disagreement till seems to exist regarding the long term effect of groynes under the conditions mentioned above. Clearly, the groynes do not directly affect the sand transport at some distance seaward of the groynes and therefore erosion seaward of the groynes will continue te occur after the construction of the groynes. Since the coastine and the depth contours must eventually attain the same rate of movement ome coastal engineers have dravn the conclusion that the effect of groynes on a receding coast will be of a temporary character only.

Thia reasoning is obviously rather superficial. A better understanding of the manner in which the coast profile develops after the construction of groynes may be obtained by considering the fundamental physical factors involved in the sand transpert outaide the breaker zone (the offshore bar).

\section{FUNDAMEATAL COMSIDERATIONS}

The water morement - The water movement cloae to the bed outside the breaker gone consist of an oscillatory motion in the direction of propagation of the waves and a longshore current. The current component in the direction perpendicular to the shore is of second order only and may be disregarded in this connection.

The longshore current may be due to a slope of the water aurface along the coast caused by astronomical and/or storm tides, or it may be due to a longahore component of the wind shear stress on the water surface. The waves do nat contribute essentially to the longshore current on a straight cosst outside the breaker zone. 


\section{THE DEVELOPMENT OF COAST PROFILES ON A RECEDING COAST PROTECTED BY GROYNES}

Under storm conditions the longshore gradient caused by the wind shear atress will often be much more important than the tidal gradient at deptha well above the breaker depth - except, of courae, when the wind is blowing approximately at a right angle to the shoreline. This is simply due to the fact that the wind gradient increases inversely proportional to the depth, whereas the tidal gradient remaina constant over the entire coast profile. This is the reason for which the direction of the current under storm conditions is aften determined by the direction of the wind at conaiderable distances from the coast irrespective of the tidal currents at larger deptha.

The bed shear stresges. The problem of the shear atresses in the combined motion of waves and current is very complicated and atill remaing largely unsolved, qualitatively as well as quantitatively. It is known, however, that the boundary layer in the waye motion is quite thin, and therefore the maximum bed shear streas $\tau_{\text {w }}$ caused by the ware motion may be expressed by

$$
\tau_{w}=\lambda_{w} \frac{1}{2} \rho U^{2}
$$

in wich $U$ is the naximun orbital velocity at the bed as calculated by the irrotational theory. Iittle i known about the magnitude of the tactor $\lambda$, but the available evidence indicates that it has a value of about 0,02 .

The approximate value of 0,02 for $\lambda$ implies that the shear stress exerted by a ware motion with the instantaneous bottom velocity $U$ is several times greater than the ahear stress exerted by ateady current with the mean velocity $U$.

The shear tress component aue to the longshore current may be inferred directly from the tidal and wind gradients along the coast. At moderate depths this ahear atress will uaually be considerably amaller than the maximum ware shear stress under storm conditiona.

The problem of a combination of waves and current has been analysed by professor H. Lundgren, chief of the Coastal Engineering Laboratory, Copenhagen, who found that the resulting maximum ahear stressea may be found by superposition of the maximum wave shear stress and the constant longshore current shear atress. Qualitatively thi superposition may be represented by fig. 1. The reaulting maximum shear stress will only be slightly different from the maximum wave shear atres.

The direction of the maximum shear stresa indicates the direction of the maximum particle velocity near the bed. This ipplies that for constant $\tau$ the velocity $v$ of the longshore current is approximately proportional to the first power of the longshore current ghear stress $\tau_{c}$. 
The sand tranaport function. Very little definite knowledge exists concerning the transport capacity of a combined wave and current motion. Therefore, the only way in which it is possible at preaent to establish a reasonably sound hypothetical relationship is to utilize the existing knowledge of and transport in uniform open channel flow.

Using the terminology of R.A.Bagnold (1957) we will define the bed lood grains as that part of the moving grains whose submerged weight is transferred to the bed as a grain stress in the dispersion near the bed. The suspended load grains are the grains whose settling through the water is balanced by the turbulent diffusion.

In the case of uniform grains with the diameter $D$ and the specific gravity Bagnold found that, when the bed shear stress $\tau_{0}$ is large in terms of the stress upit $(s-1) \gamma D$, the bed load. transport and the suspended load transport are both proportional to $\tau_{0} 3 / 2$. Since $\tau_{0} 1 / 2$ represents the velocity of the fluid this result may be interpreted in the way that the load (the aubmerged weight of the moving grains per unit area of the bed) is proportional to $\tau_{0}$ and that it move with a relocity proportional to the mean fluid velocity. As far as the bed load is concerned this interpretation appeara to be physically correct. With regard to the suspended load the question of the physical validity of this interpretation is impossible to answer as long as the nature of the transition between the bed load and the suspended load (the boundary condition of the suspended load) is unknown.

There can be little doubt that with regard to the bed load Bagnold's results are directly applicable to the case of combinations of waves and current. The role of the dispersed grains near the bed is simply to provide a means of transferring the shear stress $\tau_{0}$ to stationary grains of the bed, and there seems to be no reason why this mechanism should be essentially different because of the comparatively slow variations in magnitude and direction of $\tau_{0}$ in the presence of waves.

As stated above under torm conditions the maximum wave shear stress $\tau_{w}$ at moderate depths will usually be considetably larger than the longshore current shear stress $\tau_{c}$. Consequently the major part of the bed load transport will occur when the bottom velocity in the wave motion passes its maximum. In accordance with Bagnold's results it may be assumed that the amount of bed load grains (measured by their submerged weight per nuit area of the bed) may be represented by $\tau_{w}$ and that the mean longshore velocity of the bed load grains is proportional to the velocity $V$ of the longshore current. By (1) the following expression for the bed load transport $Q_{b}$ per unit width outside the breaker zone is obtained

$$
Q_{b} \sim U^{2} V
$$

The problem of suspended load transport in combinations of waves and current is considerably more complicated. Since the thickness of the boundary layer in a rave motion without a superposed current is only a small fraction of the water depth, the diffusion coefficient becōnes very small at a short distance above the bed. Consequently the wares alone are unable to support any significant suspended load. 
THE DEVELOPMENT OF COAST PROFILES ON

A RECEDING COAST PROTECTED BY GROYNES
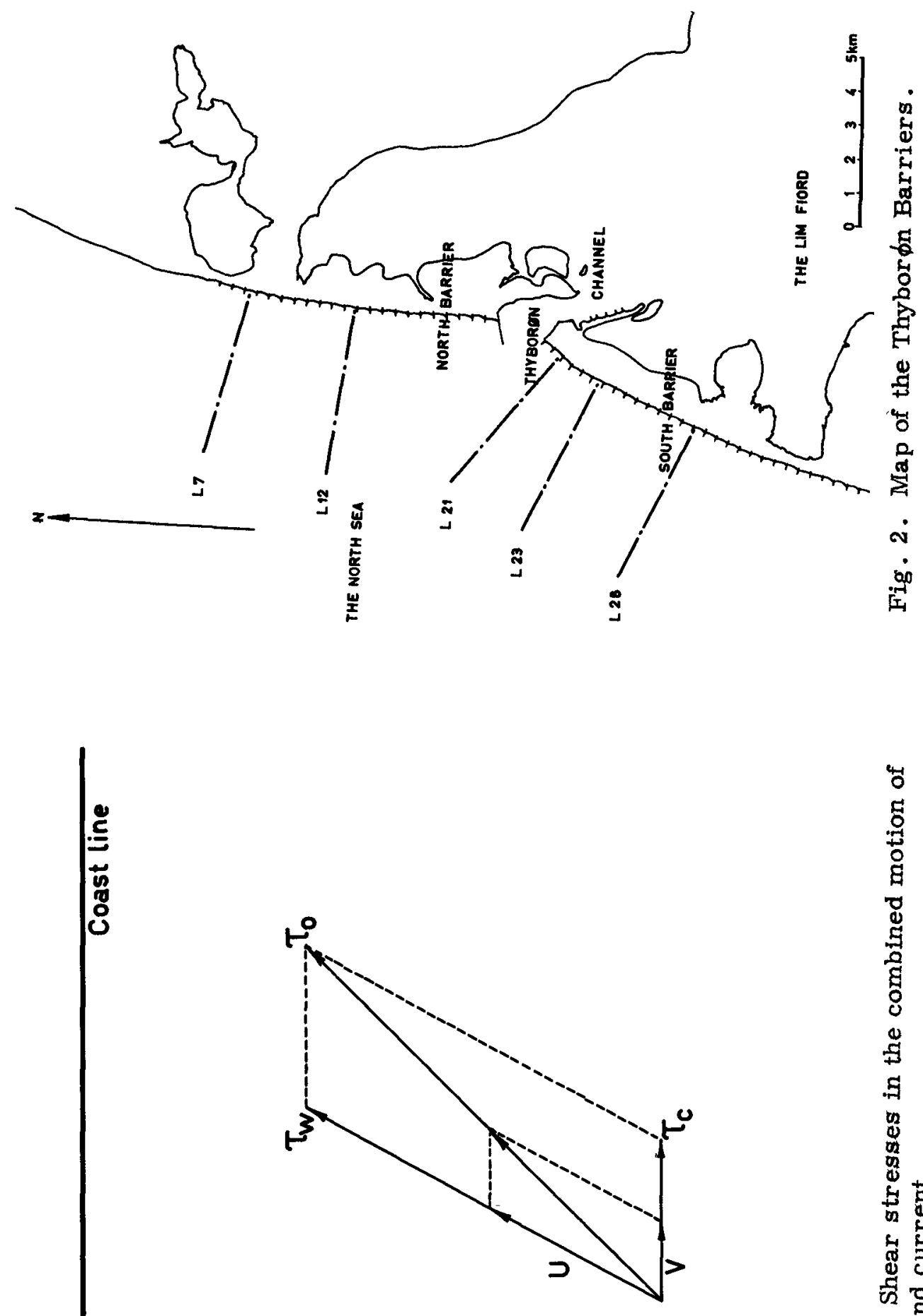

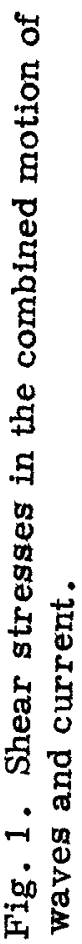


The presence of the longshore current, however, implies that turbulent diffusion takes place orer the entire depth and therefore ouspended load can be maintained at any height over the bed.

According to the differential equation for the concentration of suspended grains the turbulence is able to carry any amount of suspend load as long a the turbulence is not canceivebly attenuated by the presence of suspended material.

In the case of a combination of wares and current the bed load and the turbulence near the bed i mainly determined by the wave motion. Consequently, the concentration of suspended grains near the bed and therefore the magnitude of the concentration at any level is determined easentially by the ware motion. Applying the abore mentioned interpretation of Bagnold's results we arrive at the conclusion that the total load of suspended grains should be approximately proportional to the wave shear stress $\tau_{w}$. It mast, hovever, be expected that the ratio of current shear tress to wave shear stress $\tau_{c} / \tau_{\text {has }}$ some influence on the magnitude of the suspended load, but within the limits of interest in the present paper the influence of this ratio should be slight.

Since the mean longshore velocity of the sumended grain must be proportional to the longshore current velocity $\nabla$, we obtain for the total transport rate $Q_{t}$ of bed load and suspended load per unit width of the coast profile

$$
Q_{t} \sim U^{2} V
$$

in which the factor of proportionality depends on the grain size $D$ and the ratio $\tau_{c} / \tau_{w}$.

This relationship is a simple mathematical expression of the vel known fact that the waves put the sand into motion but the current determines the relocity and the direction of the transport.

The above expression (3) might, of course, have been given a dimensionless form by means of parameters similar to the ones used by Bagnold (1957). However, for the purposes of the present paper it is simpler to use the dimensional form (3).

\section{THE INPLUENCE OF GRONNES ON THE COAST PROFILES}

The significance of the longshore transport. Most of the previo work on coast profiles, whether in the laboratory or in the field, has been concerned mainly with the role of the transverse transport (onsho and offahore) in the shaping of the profiles. This transverse transpo has been shown to depend on the seepness of the attacking waves throu which it has been posaible to explain the seasonal flactuations of the profile shape, and it has eren been possible to correlate profile fluctuations over periods of several years with variationg in the frequency of trong onshore winds, Bruun (1954). 


\section{THE DEVELOPMENT OF COAST PROFILES ON A RECEDING COAST PROTECTED BY GROYNES}

When groynes are built on a long, continuously receding sandy coast the recession of the coastline is immediately reduced and the coast profiles become steeper. Since the primary cause of the recession of the coast alnost invariably is an increasing longshore transport capacity along the coast, it must quite obviously be expected that the long term development of the coast profiles will depend mainly on the manner in which the increasing steepness influences the longshore transport.

If it is assumed that no change in the meteorological conditions take place the only change in the wave conditions outside the breaker zone due to an increase in the steepness of the coast profiles will be that the damping of the waves by bed friction during the travel from deep water to the breaker zone is reduced. Consequently, the everage wave height juat outside the breaker zone will be somewhat higher in the seeper profile so that the longahore transport capacity will be increased.

On the other hand the waves do not contribute materially to the longshore current which is caused almost exclusively by the longshore tidal and wind gradients. If the conditions at a certain depth before and after the increase in steepness are compared, the longshore gradients will beridentical in the two cases. By fig. 1 it may be seen that the longshore current velocity $V$ caused by a certain longshore gradient $\tau_{c}$ depends on the wave shear stress $\tau_{w}$ in the following manner:

$$
V \sim \frac{\tau_{c}}{\tau_{w}} \cdot \sqrt{\tau_{0}} \sim \frac{\tau_{c}}{\sqrt{\tau_{w}}} \sim \frac{\tau_{c}}{U}
$$

Thus, if the wave height is increased the longshore current velocity decreases.

The resulting relative increase in the longshore transport capacity by (3) become identical with the relative increase in $U$, which is the ame as the relative increase in the wave height $B$.

Since the width of that part of the coast profile in which the ateepness increases is usually rather amall (a few kilometres) the increase in the average wave height and transport capacity corresponding to a substantial increase in the slope of the bed will normally be in the order of a few per cents only.

If we consider two coast profiles a unit length apart the annaal depth increase at a certain depth $d$ due to the difference $\Delta Q_{t}$ in transport capacity per unit width per year between the two profiles will equal $\Delta Q_{t}$. When the teepness increases, $\Delta Q_{t}$ must obviously increase in the same rate as $Q t$, that is, much more slowly than the teepness.

The rate of movement of the d depth contour will be equal to $\Delta Q t / \tan \alpha$, where $\tan \alpha$ is the slope of the bed at the depth d meters. It is evident from the above that this expression decreases with increasing steepness. 


\section{COASTAL ENGINEERING}

Thas, we are led to the conclusion that the effect of the groynes on the profile outside the breaker zone will be that the rate of movement of the depth contours will decrease, until it eventually becomes equal to the annual recession of the coastline.

The increasing steepness of the coast profile mast, of course, be expected to influence the magnitude of the annual recession of the coastline. Firat, the average wave height will be greater in the steeper profile. Since the beach drift is probably proportional to about the 3 rd power of the wave height an increase in the wave height of a few per cents may increase the coastline recession with 10-20\%.

Second, the equilibrium between onshore and offshore sand movement, which might have existed before the construction of the groynes, will probably be disturbed by the increased steepness. There seems to be no way in which the importance of this factor can be evaluated theoretically. However, empirical evidence seems to indicate that the transverse transport is on the whole of very little importance with regard to the coastal erosion, and therefore this factor may generally be expected to be rather unimportant.

In concluaion it may be aid that the effect of construction of groynes on a continuously receding sandy coast will be a permanent reduction of the rate of movement of the coastline. When the steeper equilibrium profiles of the protected coast have been reached, the annual recession of the coastline will probably be a little greater than shortly after the installment of the groynes, but still considerably less than that of the unprotected coast, depending on the efficiency of the groynes.

It is interesting to note that since the width of the coast profile decreases much more that the transport capacity increases when the steepness is increased, the total longshore transport will be less in the steeper profile. Thus, the groynes will reduce the longshore movement of sand over the entire coast profile, not only on the beach.

These results are confirmed conclusively by the development of the groyne protected North Sea coast of the Thyboron Barriers in Denmark, which will be described briefly below.

\section{COAST DEVELOPMGANT ON THE THYBORON BARRIFRS}

A detailed account of the coast development on the Thyboron Barriers has been given by Bruun (1954).

The Thyboron Barriers are located on the northern part of the Danish North Sea coast. A map showing the present shape of the coastline is given in $\mathrm{fig.} 2$.

The Thyborøn Channel, which separates the North and South Barrierg, connects the Limfjord, which has water surface of some $1200 \mathrm{~km}^{2}$, with the North Sea. This channel was formed in 1862 during a severe gale. Since the tidal range at Thyboron is very small - about $25 \mathrm{~cm}$ - the cross section of the channel is determined 


\section{THE DEVELOPMENT OF COAST PROFILES ON A RECEDING COAST PROTECTED BY GROYNES}

by the flow under storm tide conditions. With strong westerly gales storm tides of more than 2 meters above MSL may occur accompanied by discharges of up to about $13.000 \mathrm{~m} / \mathrm{s}$ in the channel.

The direction of the littoral drift on about $10 \mathrm{~km}$ of coastline on each side of the channel is towards the channel. Since the current in the channel during strong onshore winds is invariably ingoing, all the sand - about $800.000 \mathrm{~m}^{3}$ per year - eroded on these $20 \mathrm{~km}$ of coast is carried through the channel to the shoals in the Limfjord.

The formation of the channel caused a strong erosion of the coast of the barries, which led to the construction of a system of heavy concrete groynes on these coasts around 1900. Since then the Board of Maritime Works has kept the development under close control by frequent soundings and measurements of the location of the coastline.

Fig.s 3 and 4 show some results of these observations for a typical stretch of the North and the South Barrier, respectively, at some distance from the channel. Similarly, fig. 5 represents the coast development off Thyboran town on the northern end of the South Barrier. The location of these stretches is shown on fig. 2 . The curves on fig.s 3,4 and 5 represent the averages of the results of all measurements on the considered stretches. The results of a survey made in 1874 have been included to show the effects of the groynes on the coastline recession.

The dashed line in these figures is a plot of the location of the coastline as measured from the coastline in 1874. This ghows that while the unprotected coast receded at a rate of about 10 meters per year, the rate of recession after the construction of groynes has been only about 2 meters per year. Although the measurements of the location of the coastline - which are very numerous - have been smoothed considerably before plotting, the movement of the coastline is still somewhat irregular. It is not possible in the later years to detect any tendency towards a general acceleration of the coast recession that may be distinguished from the irregular variations that have previously occured.

The full line are plots of the distances from the coastline at the time of the sounding to the 6,8 and 10 meter depth contours. Thus, the vertical distances between these lines directly represent the reciprocal value of the slope of the bed.

The slope of the bed at the $8 \mathrm{~m}$ depth contour has now increased to about twice the original value or more since the construction of the groynes about 1900. This has been accompanied by a very marked stabilization of the distance to the 6 m depth contour, and the figures also show a more or less clear tendency towards a general reduction in the rate of movement of the $8 \mathrm{~m}$ contour relative to the coastline. On the whole, there seems to be no doubt that the profiles are now approaching their equilibrium shape up to depths of 9 to 10 meters. 


\section{COASTAL ENGINEERING}

A calculation of the wave attenuation by bed friction according to (1) for a 3 meter high wave with a period of 8 seconds and an angle of incidence of $45^{\circ}$ has been made to illustrate the influence of the profile development on the wave heights. The result was, that while this wave, which is quite representative of a medium strong gale at Thyboren, would in 1900 lose $11 \%$ of its height travelling from a depth of 20 meters to the 6 meter contour, it would between the same depth contours in 1950 lose only $6 \%$.

According to the previous analysis a change in the wave height of this magnitude should involve an increase in the average annual erosion of 5\%. Since the slope of the bed has been donbled in the same period, the (absolute) rate of movement of the 6 meter contour

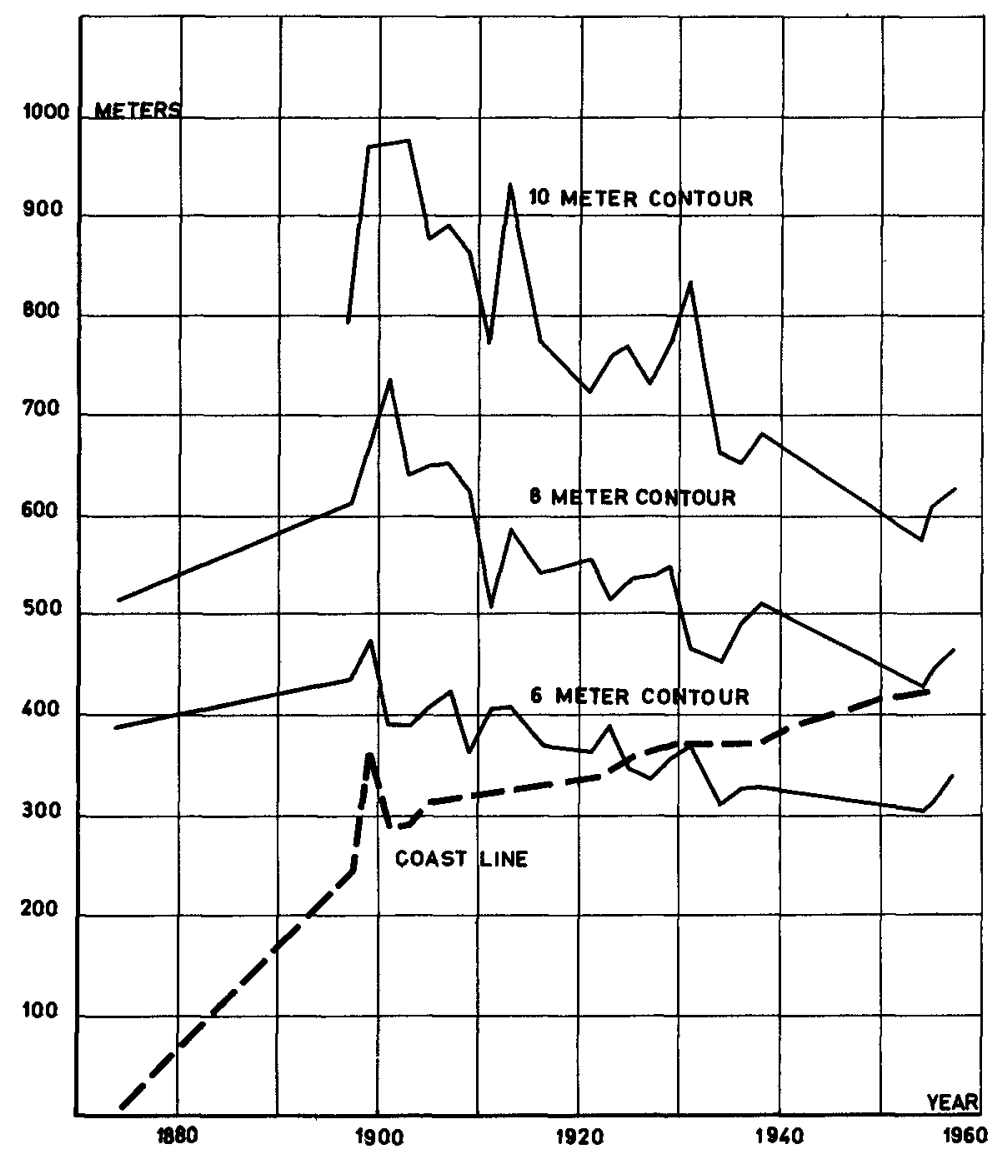

Fig. 3. Coast development on the North Barrier between L 12. Full lines show variation of distances from the coastline to various depth contours. Dashed line is a plot of the distance from the coastline to the original coastline in 1874 . 
THE DEVELOPMENT OF COAST PROFILES ON A RECEDING COAST PROTECTED BY GROYNES
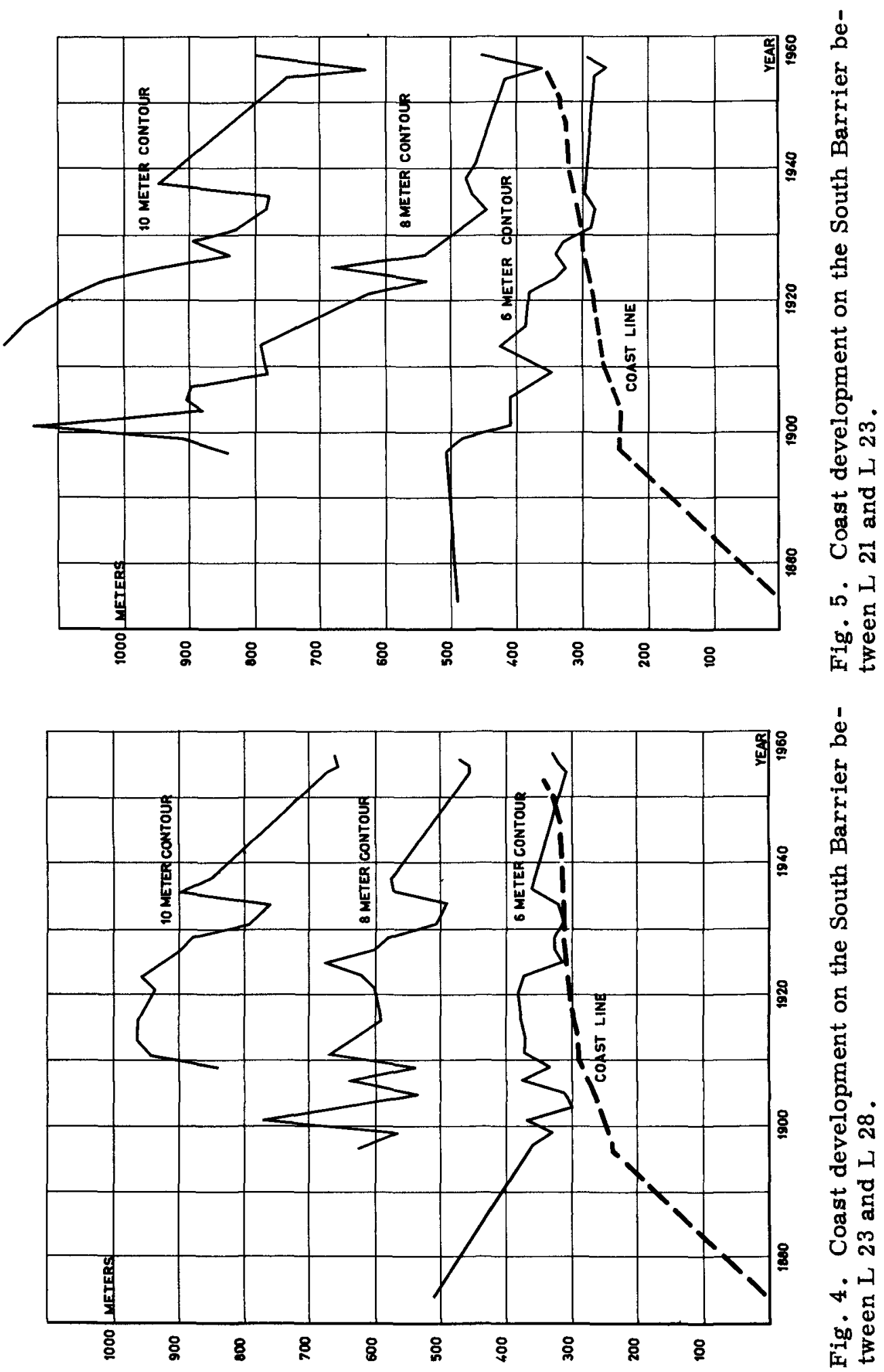


\section{COASTAL ENGINEERING}

should be expected to have been reduced by a little less than half of its original value. Because of the fact that the coastline also recedes, the reduction in the annual recession of the $6 \mathrm{~m}$ contour relative to the coastline should be considerably larger, which has, in fact, also been the case.

It is remarkable that the increase in steepness of the coast profiles has not caused any conceivable acceleration of the movement of the coastline. This may possibly be due to the fact that, as the coast recedes, the groynes are becoming longer, although the outer ends of the groynes are now submerged.

\section{MODEL TESTS}

The problem of the coast development on the Thyboren Barriers has been investigated in a scale model at the Waterloopkundig Laboratorium De Voorst, Holland, for the Danish Board of Maritime Works. The results of this investigation has been that the coast recession would in the future be reduced to a lower value than the present one. In all probalility, however, this result must be attributed to the fact that in the model the outer ends of the groynes were maintained in their original position, so that the coast protection in the model was more effective than in the prototype.

The main point is that the model gives no indication of any significant future increase in the coast recession, in which it agrees completely with the results of the analysis in this paper.

\section{CONCLUSION}

The construction of groynes on a continuously receding sandy coast will cause a permanent reduction of the rate of recession of the coastline. The groynes reduce the longshore sand transport not only on the beach, but also, indirectly, orer the entire coast profiles. The shape of the equilibrium profile of the protected coast is determined almost exclusively by the longshore transport and the efficiency of the groynes.

\section{ACKNOWLEDGMENTS}

The author is indebted to professor, dr.techn. H. Lundgren, chief of the Coastal Fngineering Laboratory, Copenhagen, for his support in the preparation of the present paper. Furthermore he is indebted to the Danish Board of Maritime Works for the opportunity to gain access to the data from the coast at Thyborøn.

\section{REFHAENCES}

Bagnold, R. A. (1957). The flow of cohesionless grains in fluids: Philosophical Transactions of the Royal Society of London, Series A, rol. 249, pp. 235 - 297.

Bruan, P. (1954). Coast Stability. Copenhagen 1954. 